\title{
Sources of variation in rapidly inducible responses to leaf damage in the mountain birch-insect herbivore system
}

\author{
S. Hanhimäki and J. Senn* \\ Laboratory of Ecological Zoology, Department of Biology, and Kevo Subarctic Research Station, University of Turku, \\ SF-20500 Turku, Finland
}

Received June 20, 1991 / Accepted in revised form March 2, 1992

Summary. Studies on rapidly inducible resistance in trees against insect herbivores show substantial variation in the strength of responses. Here we report the results of a study which examined causes of this variation. We bioassayed the quality of leaves of two developmental phases (young vs. mature) of the mountain birch Betula pubescens ssp. tortuosa by measuring the growth of two instars of Epirrita autumnata larvae. We used only short shoot leaves from trees of a natural stand, uniform in size and age. Damage was caused by larvae and artificial tearing of leaf lamina, varying the scale and time. We separated seasonal changes in plants from instar-dependent effects of the animals by testing experimental larvae in two subsequent growth trials. We found that only larval-made damage induced responses in leaves that made the leaves significantly poorer quality for the test larvae. Artificial damage induced only weak responses, and artificial canopy-wide damage even caused slight improvement of leaf quality. Cumulative leaf damage did not strengthen birch responses. Leaves that were in the expansion phase responded to damage while fully-expanded, mature leaves showed no response. The pattern of responses indicated that there might be physiological constraints: small-scale damage induced resistance against the larvae but largescale damage did not. Prevalent weather conditions might have modified these responses. Larvae of two instars and sexes, of low- and high-density populations responded to leaf damage similarly. However, prior experience of larvae with the host plant may have affected subsequent larval performance. Variation in rapidly inducible responses in birches was caused by plant characters rather than by test animals.

Key words: Betula pubescens - Epirrita autumnata - Rapidly inducible responses - Phenology - Conditioning

The role of inducible resistance in host plants has received much attention in plant-herbivore studies in recent years

* Correspondence to: Swiss Federal Institute for Forest, Snow and Landscape Research, $\mathrm{CH}-8903$ Birmensdorf, Switzerland (reviews in Karban and Myers 1989; Haukioja 1991). In theory, inducible resistance should occur only when needed, so that the costs of producing resistance against herbivores should be minimized. Inducible resistance can be divided into two types, rapidly and delayed inducible resistance (RIR and DIR, respectively), depending on the response time (hours to days or years) and the effects on herbivore population dynamics (stabilizing or destabilizing) (see Haukioja 1982). RIR affects the triggering herbivore generation whereas DIR affects the following generation(s). Some of the inadequacies in studies on inducible resistance may be attributable to the insufficient separation between these two response types. This is true of experiments in which the same trees have been treated twice (e.g., Faeth 1986; Hartley 1988).

Most studies on delayed inducible resistance (DIR) have clearly demonstrated negative impacts on herbivore performance: reduced growth rate, longer larval period, reduced pupal mass associated with lowered fecundity, and lower survival (e.g., Schultz and Baldwin 1982; Valentine et al. 1983; Neuvonen and Haukioja 1984; Haukioja and Neuvonen 1985; Haukioja et al. 1985; Neuvonen et al. 1987, 1988; Hanhimäki 1989): In these studies rigorous controls were used and treatments to trees were assessed randomly by the experimenter (not by the herbivores themselves).

In contrast to DIR, the results on RIR have not been as consistent. It has been shown that RIR can affect the performance of the herbivore species that trigger the response in their host plants (Haukioja and Niemelä 1977, 1979; Haukioja 1980, 1982; Karban and Carey 1984; Raupp and Denno 1984; Haukioja and Hanhimäki 1985; Bergelson et al. 1986; Fowler and MacGarvin 1986; Rossiter et al. 1988) and of species that feed on the plants subsequently (e.g., Brody and Karban 1989; Hanhimäki 1989; Karban and English-Loeb 1990). Rapid woundinduced responses in host plants may affect acceptability or palatability to herbivores (Edwards and Wratten 1983, 1985; Wratten et al. 1984; Edwards et al. 1985), behavior (Raupp and Sadof 1989), and distribution of species within the plant (Gibberd et al. 1988).

The retarding effect of RIR on herbivore growth may be modest (Fowler and Lawton 1985), but the impact on 
herbivore performance may be strong enough to interfere with herbivore population dynamics by forcing the herbivores to move more and by exposing them to other regulative factors (Wratten et al. 1988). Although rapidly induced chemical changes (nutritional or toxic) have been detected in response to damage in tomato (Green and Ryan 1972; Broadway et al. 1986), birch (Niemelä et al. 1979; Hartley and Lawton 1987, 1991; Hartley and Firn 1989), and red oak (Schultz and Baldwin 1982; Rossiter et al. 1988), their effects on herbivore performance are far from clear (Lawton 1986; Hartley and Lawton 1987, 1991).

Given the large number of herbivorous insects sharing birch as their host plant (Kennedy and Southwood 1984), it is unlikely that all the herbivores should be similarly affected by rapidly inducible reactions. This would suggest universal reaction of plants against leaf predators. Neuvonen et al. (1988) and Hanhimäki (1989) showed that most of the insect herbivores tested on the mountain birch had retarded growth on leaves that had experienced DIR, but only few species were negatively affected by RIR (Hanhimäki 1989; S. Hanhimäki unpubl. data). Not only different species but also different larval instars (Rossiter et al. 1986, but see Hartley and Lawton 1991), sexes (Thompson et al. 1990), and populations may exhibit different sensitivity to changes in leaf quality, and to RIR.

The most striking point in the results on RIR is the variation in the effect of responses. This variation can be attributed to plant characters or to herbivores used in the experiments. Here we present the results of a test of putative rapidly inducible resistance against the autumnal moth (Epirrita autumnata (Borkhausen), Geometridae) for a deciduous tree species, the mountain birch (Betula pubescens ssp. tortuosa (Ledeb.) Nyman, Betulaceae). We examined several potential sources that may create variation in triggering the RIR, i.e. whether timing and degree of damage, cumulative versus single defoliation, artificial versus insect-made, and time since damage influence the efficacy of RIR. We tested only even-aged leaves from short shoots of birches of an old natural stand. We bioassayed leaf quality using two larval stages and sexes of the autumnal moth. We tested also whether autumnal moth larvae from two (low- and high-density) populations and with different prior experience with leaf quality differ in their responses.

\section{Sources of variation in RIR}

There may be differences among plant species in their responses to leaf damage (e.g., in deciduous trees) (Edwards et al. 1986), among plant populations with different outbreak history (Haukioja et al. 1983; Haukioja and Hanhimäki 1985) and plants growing at different sites (Haukioja et al. 1983). General growth conditions such as plant crowding (Karban et al. 1989), growing in greenhouse versus field (Marshall 1989) and in pots versus freely (Baldwin 1988a) have been shown to influence plant responses to defoliation or to leaf damage. Similarly, plant age (Fowler 1984; Karban 1987), size and even shape (Marshall 1989) may affect these responses. There may be differences in leaves of different age, i.e. in long or short shoots of birches (Hartley and Lawton 1987).

Differences in damage responses may be due to intraseasonal variation in leaves; for instance, late season damage did not alter the performance of several late season herbivorous insects (Haukioja and Niemelä 1979; Neuvonen et al. 1988). Similarly, leaves in the sink-source transition phase have been shown to be differently vulnerable to damage (Coleman 1986). Furthermore, Wratten et al. (1984) and Edwards et al. (1986) reported differences in the efficacy of RIR reflected by the time since damage. Rossiter et al. (1988) found that the amount of damage correlated negatively with herbivore performance. In addition, Hartley and Lawton (1987) presented data that suggested differences in chemical responses of birches due to larval versus artificial leaf damage.

\section{Methods}

Study site

All experiments were conducted at the Kevo Subarctic Research Station in northern Finland $\left(69^{\circ} 45^{\prime} \mathrm{N}, 27^{\circ} 01^{\prime} \mathrm{E}\right)$ in 1987 . The study area is covered with low mountain birch forest with a few scattered pines (Pinus sylvestris L.), and it is on the northern face of the hill Puksalskaidi. Cold northerly winds may kill the eggs of the autumnal moths at this exposed site (Tenow 1975; Tenow and Nilssen 1990 ) so that $E$. autumnata outbreaks have not affected the site for at least 22 years. The densities of other herbivorous insect species have also been low in the study area. Thus, it was improbable that extensive natural grazing could have triggered the responses we recorded.

\section{Induction treatments to trees}

Altogether 150 trees were chosen in an open canopy forest in a study area covering approximately 2 ha. The trees $(1.5-2 \mathrm{~m}$ in height) were randomized into five treatments within ten blocks. The treatments included a range of damage, from no damage to partial localized and to canopy-wide damage. Treatments are detailed later; here we simply list the number of trees and their treatments in each block. No damage: (1) four control trees (abbreviation CON used here); partially damaged trees: (2) four trees in which leaves of two branches were damaged manually (MAN); (3) four trees in which leaves of two branches were damaged by larvae (LAR); canopy-wide damaged trees: (4) one tree whose leaves were twice manually damaged (CUM); and (5) two trees whose leaves were once manually damaged (TOT). We always treated and tested the trees in blocks $1-5$ first, and trees in blocks 6-10 the next day. Because we had to remove leaves from control trees for bioassays, we used new control trees every time (see Neuvonen and Haukioja 1985, 1991).

We applied damage to trees on two occasions: firstly, when leaves were in the growth phase (I1 in Table 1) and secondly, when leaves were fully matured (I2). The first damage was done on June 22-25 and the second on July $1-4$. On each occasion half of the trees in a block were treated. The CUM trees were exceptional in that we treated the same trees twice (Table 1). The timing of treatments can also be expressed by the thermal sum to the base of $5^{\circ} \mathrm{C}$ (dd5) (Table 1), to facilitate comparisons with other studies (e.g., Haukioja et al 1985; Haukioja and Neuvonen 1985; Ruohomäki et al. 1992). Table 1 summarizes the treatments with damage levels and timing of damage and growth trials.

Partial localized damage. On LAR trees ten E. autumnata larvae were allowed to feed for 2 days in bags (two bagged branches per tree) to produce natural localized damage. On MAN trees we tore 
Table 1. Summary of the damage treatments, damage levels estimated for the whole tree, days since damage, and number of trees tested
I1. Damage to young leaves on $22-25$ June $(93-106$ dd5)

\begin{tabular}{lccccc}
\hline Treatments & CON & LAR & MAN & CUM $^{\mathrm{a}}$ & TOT \\
\cline { 2 - 6 } Damage level (\%) & 0 & $<5$ & $<5$ & 15 & 30 \\
Days since damage: & 4 & 4 & 4 & 4 & 4 \\
$\quad$ June 26 trial & 13 & & 13 & & 13 \\
$\quad$ July 5 trial & 20 & 20 & 20 & 10 & 10 \\
Number of trees & & & &
\end{tabular}

I2. Damage to mature leaves on $1-4$ July $(121-131$ dd5)

\begin{tabular}{lccccc}
\hline Treatments & CON & LAR & MAN & CUM $^{\text {a }}$ & TOT \\
\cline { 2 - 6 } Damage level (\%) & 0 & $<5$ & $<5$ & 30 & 30 \\
Days since damage: & & 4 & 4 & 4 & 4 \\
$\quad$ July 5 trial & 4 & 20 & 20 & 10 & 10 \\
Number of trees & 20 & &
\end{tabular}

a The same trees treated twice

Treatments: $\mathrm{CON}=$ control; localized damage: $\mathrm{LAR}=$ larval made damage, $\mathrm{MAN}=$ manual damage; canopy-wide damage: CUM = cumulative and TOT = "total" damage (see Methods for details). Degree-days (dd5) at the time of treatments about $50 \%$ from a single leaf in every short shoot of two branches to produce artificial localized damage. In MAN trees the damage was spread evenly over the experimental branches, whereas in LAR trees the damage was patchy owing to larval behavior. The mountain birch has three or four leaves on each short shoot; thus, the LAR and MAN trees experienced damage to less than $5 \%$ of the total leaf biomass estimated for the whole tree, but on each experimental branch about $30 \%$ of the leaves were damaged.

Mesh bags were used only to keep the RIR-triggering larvae on the branches for 2 days. Enclosing birch branches in mesh bags for several weeks has not been found to affect leaf quality for E. autumnata larvae (S. Hanhimäki et al. unpubl. data). Therefore, no other experimental trees received bags.

From partially damaged trees (LAR and MAN) only leaf clusters of one branch were tested; those of the other branch were used later in the season in another experiment, which will be dealt with separately.

Canopy-wide damage. We tore about $50 \%$ from a single leaf on every second short shoot of the cumulatively damaged trees (CUM), and a similar amount from a single leaf but on every short shoot of the TOT trees. In both groups the damage was spread over the whole tree canopy. About $30 \%$ of the leaves in TOT trees experienced damage, while $15 \%$ of the leaves of the CUM trees experienced damage at the first (I1) and a further $15 \%$ at the second treatment (I2).

\section{Larval material in bioassays}

Quality of the mountain birches was bioassayed with larvae of two (penultimate and ultimate) instars of $E$. autumnata, a univoltine outbreak species on the mountain birch in northern Fennoscandia (Tenow 1972; Haukioja et al. 1988a). Larvae hatch at the time of birch bud burst (late May-early June in Lapland), grow rapidly through five instars during 4-5 weeks and then drop into the litter and pupate. Adults fly from mid-August to mid-September. The eggs overwinter.

We used solitarily reared larvae because they are more sensitive to small changes in leaf quality than larvae reared in groups (see Haukioja et al. 1988b). Pre-experiment feeding and other growth conditions, except temperature (see below), were identical for all the larvae.

We tested larvae from a low- and a high-density population. Because populations were not replicated within densities, we do not draw conclusions about the specific attributes of low- versus highdensity herbivore populations. They were selected solely to reflect broad-spectrum variation among test animals and their potential interactions with plant responses.

Low-density population. We had 30 broods of $E$. autumnata derived from matings between laboratory-reared unrelated females and wild caught males from the Kevo area. From every brood we reared 50 larvae in plastic vials $(48 \mathrm{ml})$ from hatching ( 5 or 6 June) to pupation or to the end of the growth trial. Altogether 1500 larvae were used.

On June 16 (when larvae were in their second instar) each brood was split into three groups. These groups were kept at different temperatures to produce the two instars used in the bioassays (Table 2). The advanced larvae were kept at a warmer temperature than the others to get them into the fifth instar for the first (26 June) growth trial. The normal larvae grew in synchrony with birch trees. About half of the normal larvae were used also in the second ( 5 July) trial when they were in the fifth instar. The delayed group of larvae were kept at a cooler temperature for most of their larval period to have them in the fourth instar in the second trial. The extent of asynchrony of larvae used here is not abnormal: it is not uncommon to find larvae in their third, fourth and fifth instar at the same time on a tree in nature (S. Hanhimäki and J. Senn, pers. obs.).

High-density population. This group of test animals was derived from matings between individuals collected as larvae in the previous season in an outbreak area of E. autumnata some $80 \mathrm{~km}$ north from the Kevo experimental area, in Luftjokdalen (Norway). Altogether we had 210 larvae from 29 broods. We used these larvae only in the 26 June experiment when they were in their fourth instar (Table 2).

\section{Bioassays}

After the induction treatments I1 (damage to young leaves) and I2 (damage to mature leaves) we started the bioassays on 26 June and 5 July, respectively, 4 days after leaf damage (Table 1). Birches of three treatments of I1 (CON, MAN, TOT) were tested also on 5 July, 13 days after damage (Table 1). In the damage treatments the leaves had either larval feeding marks or one torn leaf per leaf cluster. In control clusters all the leaves were intact. Experimental larvae got whole short shoots and could thus choose among the leaves within a cluster. We measured E. autumnata growth rates over $48 \mathrm{~h}$. We chose a short-term growth trial for leaf quality testing 
Table 2. The design for growth manipulation to get the right instars of Epirrita autumnata test larvae at the right time. Each brood of the Kevo (low-density) population was divided into three groups and reared at different temperatures

\begin{tabular}{lccccc}
\hline Growth trial & June 26 & & & \multicolumn{2}{c}{ July 5 } \\
\cline { 1 - 2 } \cline { 5 - 6 } Kevo population & $n$ & Instar & $n$ & Instar \\
\hline Advanced & 240 & 5 th & - & - \\
Normal & 240 & 4 th & 390 & 5 th \\
Delayed & - & - & 390 & 4 th \\
\hline
\end{tabular}

Luftjokdalen population

Normal 210

4th

$-$

Thirty broods of the Kevo population and 29 broods of the Luftjokdalen (high-density) population were used. $n=$ number of larvae. $(-)$ Not tested

because leaf removal from experimental trees, especially in a longterm trial, may trigger inducible reactions (Neuvonen and Haukioja 1985, 1991).

We fed three larvae of both 4th and 5th instars with leaves from each experimental tree. Within one block all three larval replicates came from different broods but the three broods were the same for each tree in that block. Among blocks the broods differed. The 4th and 5 th instar larvae on a tree in the low-density population were siblings. We randomized the order of larval instars and which of the two E. autumnata populations was first given the experimental short shoot.

We weighed the larvae individually to the nearest $0.1 \mathrm{mg}$. The vials with larvae and leaf clusters were placed in weighing order on trays ( $10 \times 10$ vials/tray) and kept in the laboratory under continuous light and at temperature of $12^{\circ} \mathrm{C}$. After $48 \mathrm{~h}$ we re-weighed the larvae. To determine sex, $24 \%$ of the larvae of the high-density population and $12 \%$ of the low-density population were randomly chosen and reared to adults.

\section{Treatment of the data}

We calculated the relative growth rate (RGR) for each larva as $\left(\ln W_{t}-\ln W_{0}\right) / T$ where $W_{0}$ is the larval fresh weight at the beginning, $W_{t}$ the larval fresh weight at the end of the trial, and $T$ the time between these two measurements. All the values of RGR are expressed as relative growth in $24 \mathrm{~h}$. Data on molting larvae were deleted.

Although we stored $E$. autumnata larvae ready for a trial in a growth chamber at temperature below $3^{\circ} \mathrm{C}$, they ate and gained weight during this time. Because of this and since there exists a significant negative correlation between initial larval mass and relative growth rate (Ayres et al. 1987), we removed the effect of size within an instar and population by regressing the RGR on the initial larval mass (across treatments) throughout the analyses.

The data were normally distributed and analyzed with ANOVA for unequal cell sizes (General Linear Models Procedure, SAS 1985). Square-root transformed data (to avoid heteroscedasticity of rates; Sokal and Rohlf 1981, p. 403) gave similar results as untransformed. Thus, all analyses are based on untransformed data. We used treespecific means of larval RGR as replicates to avoid pseudoreplication (Hurlbert 1984; Neuvonen and Haukioja 1985). Since the treatments were arranged in blocks, we also included the factor block in the analyses. Blocks differed when tested over the error MS, but in none of the cases was the interaction block-by-treatment significant, indicating uniform reaction of the trees among blocks. For clarity, we have excluded the effect of blocks in the ANOVA tables. We treated phenology of the trees $(=$ induction time), treatment $(=$ dam- age type), instar, and population (we chose the larvae from two density regimes, not from random populations) as fixed factors. Thus, the data represent Model I ANOVA with trees as error terms (Sokal and Rohlf 1981). We used a priori contrasts to test for specific treatment effects.

\section{Results \\ Plant characters}

Birch phenology. Figure 1 shows the relative growth rates of the two instars of $E$. autumnata larvae on young growing (Fig. 1a) and on mature leaves (Fig. 1b). Tables $3 a$ and $3 \mathrm{~b}$ give the corresponding results for the ANOVAs. Leaf age per se affected the growth of larvae since phenology of the trees was highly significant $(F=12.62, P=0.0005$, Table 4). The difference in response of the leaves of the two phenological phases to leaf damage was demonstrated by the two-way ANOVA $(F=2.86, P=0.0399$, Table 4$)$. We did not include the CUM trees in this analysis since they were treated twice, both in I1 and I2. Due to the significant phenology-by-treatment interaction we analyzed the effect of leaf damage separately for the two induction times.

Young leaves. When treatments were applied to young growing birch leaves, the effect was significant as measured by the growth of E. autumnata larvae (Table 3a). However, control trees did not differ from damaged trees: contrast between CON and MAN + LAR + CUM + TOT was non-significant. Hence, the significant treatment effect depended on differences between damage treatments.

The specific contrast testing differences between artificial and natural damage, i.e. MAN versus LAR treatment, was significant (at $P<0.05$ ) (Table 3a). On LAR trees larval growth was poorest (Fig. 1a). Thus, larval-made damage clearly negatively affected the performance of subsequent $E$. autumnata larvae compared with the effect of artificial damage.

Partial damage, applied only to single branches, lowered the leaf quality for larvae while on leaf clusters from canopy-widely damaged trees the larvae grew better. Contrast between MAN + LAR and CUM + TOT was significant (Table 3a).

The best growth of larvae was on CUM and TOT trees (Fig. 1a), but the specific contrast between these treatments was non-significant (Table $3 a$ ). Thus, there were no differences whether damage took place cumulatively or only once.

Mature leaves. Seven days after the first treatment, damage caused to mature leaves did not affect the growth of larvae significantly (Table $3 b$ ). The trees supporting the poorest or the best growth of larvae varied according to larval stage (Fig. 1b). There were no significant contrasts between treatments (data not shown).

The effect of time since damage. Figure 2 shows the results for the growth of larvae on leaf clusters from trees that were tested either 4 or 13 days after damage. A repeatedmeasures ANOVA was used for this comparison since the 
A.
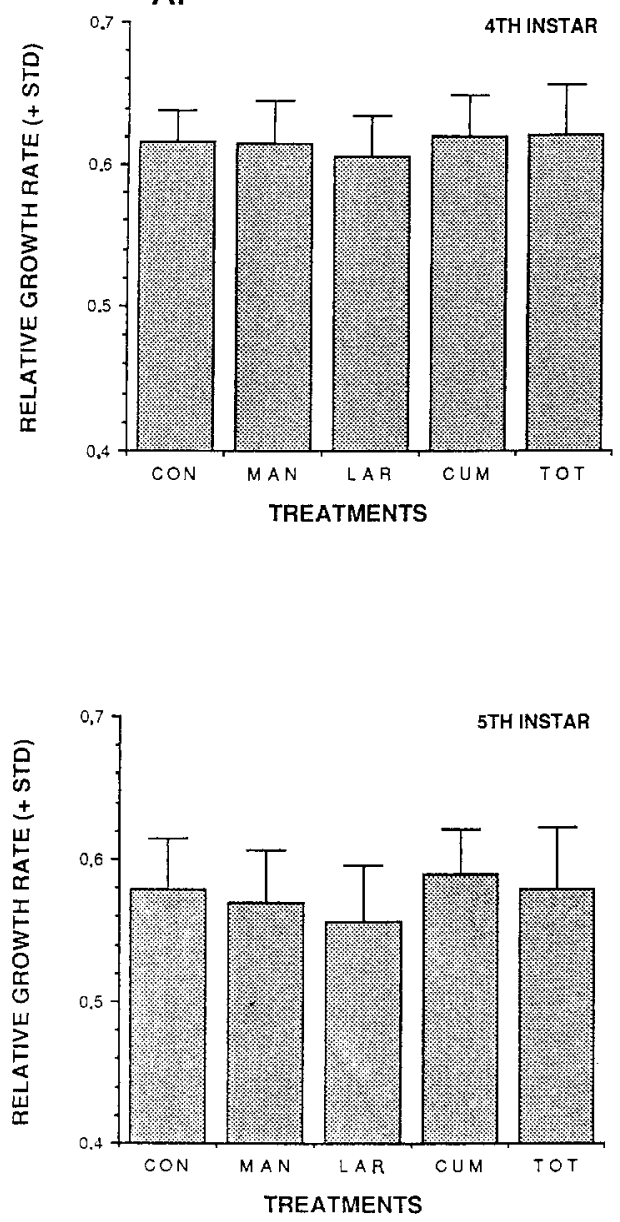

B.
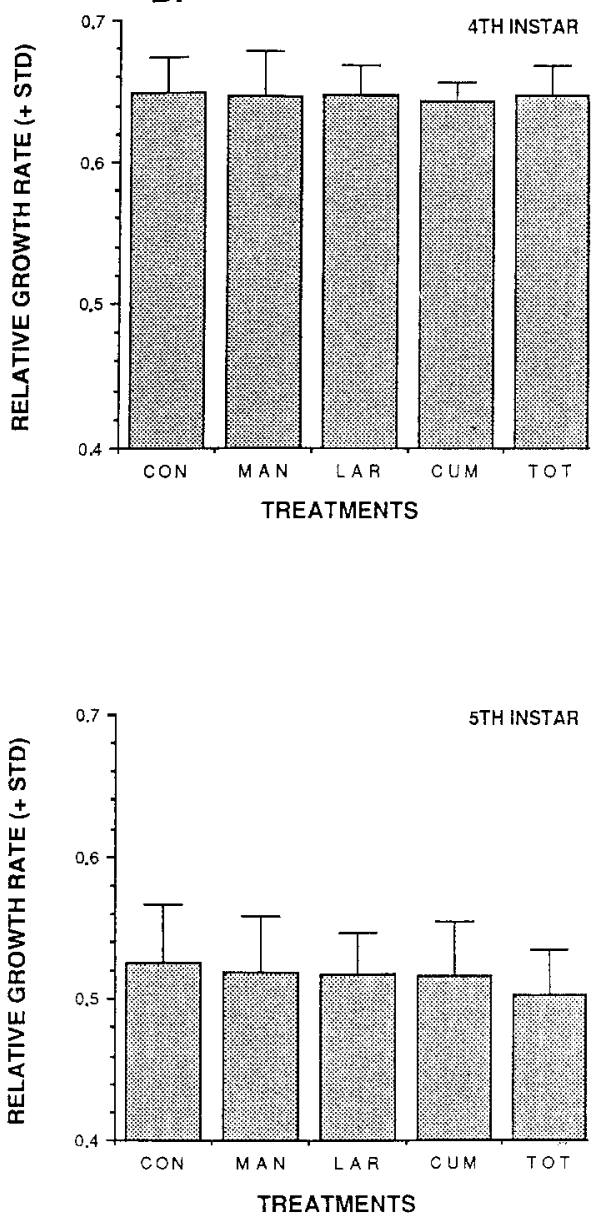

Fig. 1A, B. Mean relative growth rates (RGR) of Epirrita autumnata larvae $A$ in the 26 June (damage to young leaves) and $\mathbf{B}$ in the 5 July growth trial (damage to mature leaves). The upper part shows the results for 4th instar and the lower part for 5th instar larvae. Treatments as in Table 1. RGR values based on adjusted means. $S T D=$ standard deviation
Table 3a. ANOVA results on the effect of damage to young birch leaves on the relative growth rates of two instars of $E$. autumnata larvae in the 26 June experiment

\begin{tabular}{lrrrl}
\hline Source of variation & $d f$ & SS-III $^{\mathrm{a}}$ & $F$-ratio & $P$ \\
\hline Treatment & 4 & 10484.2 & 4.39 & 0.0035 \\
Instar & 1 & 57939.7 & 97.04 & 0.0001 \\
Treatment $\times$ Instar & 4 & 1387.3 & 0.58 & 0.6776 \\
Error $\quad 60$ & 35825.1 & & \\
$\quad$ Total & 159 & 247001.1 & & \\
Contrasts & & & \\
CON with & & & \\
$\quad$ MAN + LAR + CUM + TOT & 1 & 245.0 & 0.41 & 0.5243 \\
MAN with LAR & 1 & 2491.8 & 4.17 & 0.0455 \\
CUM with TOT & 1 & 219.3 & 0.37 & 0.5468 \\
MAN + LAR with CUM + TOT & 1 & 6841.9 & 11.46 & 0.0013 \\
\hline
\end{tabular}

${ }^{a} \times 10^{-6}$. Type III sum of squares (GLM, SAS 1985)

The model explained $85.5 \%$ of the variance. Treatments as in Table 1 . RGR values given in Fig. 1a same trees were tested twice (Table 5). (Note that LAR trees were not tested a second time because of lack of sufficient leaf clusters with larval feeding marks.) We found a significant main effect of time but no effect of damage treatment (Table 5). There was no significant interaction between time and treatment, indicating similar leaf quality for the larvae regardless of time since damage.

In this analysis larvae in the two time-of-damage groups were tested on different-aged leaves. Consequently, a significant main effect of time very probably means that maturation of leaves provoked this difference in larval growth (see also Table 4). Therefore, the effect of time after damage should be analyzed by the growth of larvae in the 5 July growth trial, in which leaf age at the time of testing was similar: only mature leaves from CON, MAN and TOT trees were assessed. The results are given in Fig. 3 and Table 6. The factor "Time" in Table 6 means the time since treatments but also the age of leaves when treated. 
Table 3b. ANOVA results on the effect of damage to mature birch leaves on the relative growth rates of two instars of $E$. autumnata larvae in the 5 July experiment

\begin{tabular}{lrrrl}
\hline Source of variation & $d f$ & \multicolumn{1}{c}{ SS-III $^{\mathrm{a}}$} & $F$-ratio & $P$ \\
\hline Treatment & 4 & 2009.0 & 0.85 & 0.4988 \\
Instar & 1 & 607323.1 & 1028.71 & 0.0001 \\
Treatment $\times$ Instar & 4 & 1536.6 & 0.65 & 0.6286 \\
Error $\quad 60$ & 35422.4 & & \\
$\quad$ Total & 159 & 814199.1 & & \\
\hline
\end{tabular}

${ }^{a} \times 10^{-6}$. Type III sum of squares (GLM, SAS 1985)

The model explained $95.6 \%$ of the variance. $R$ GR values given in Fig. 1b

This effect was non-significant. The same was true for the main effect of treatment. However, there was a significant interaction between time and treatment (at $P<0.05$ ), indicating that the effect of treatment could depend on time since damage or on leaf age when damaged or on both factors.

\section{Animal characters}

Epirrita populations. Figure 4 shows the relative growth rates of the 4th instar larvae of the low- and high-density populations and of the 5th instar larvae of the low-density Kevo population. The larvae of the two populations differed significantly in their relative growth rates (Table 7). The growth rates of the 4th instar larvae from the highdensity population were constantly higher than those from the Kevo population (Fig. 4). However, there was no significant interaction between treatment and herbivore population (Table 7), indicating similar reaction of the larvae of the two populations to leaf quality changes. Finally, larvae from the high-density Luftjokdalen population attained slightly lower pupal mass (mean $\pm \mathrm{SD}$, $70.0 \pm 6.8$ and $76.8 \pm 8.0 \mathrm{mg}$ for males and females, respectively) than larvae from the Kevo population (males: $71.9 \pm 5.9$ and females: $78.9 \pm 8.0 \mathrm{mg}$ ), although this difference was not significant $(F=1.86, P=0.1895, d f=1,18)$.
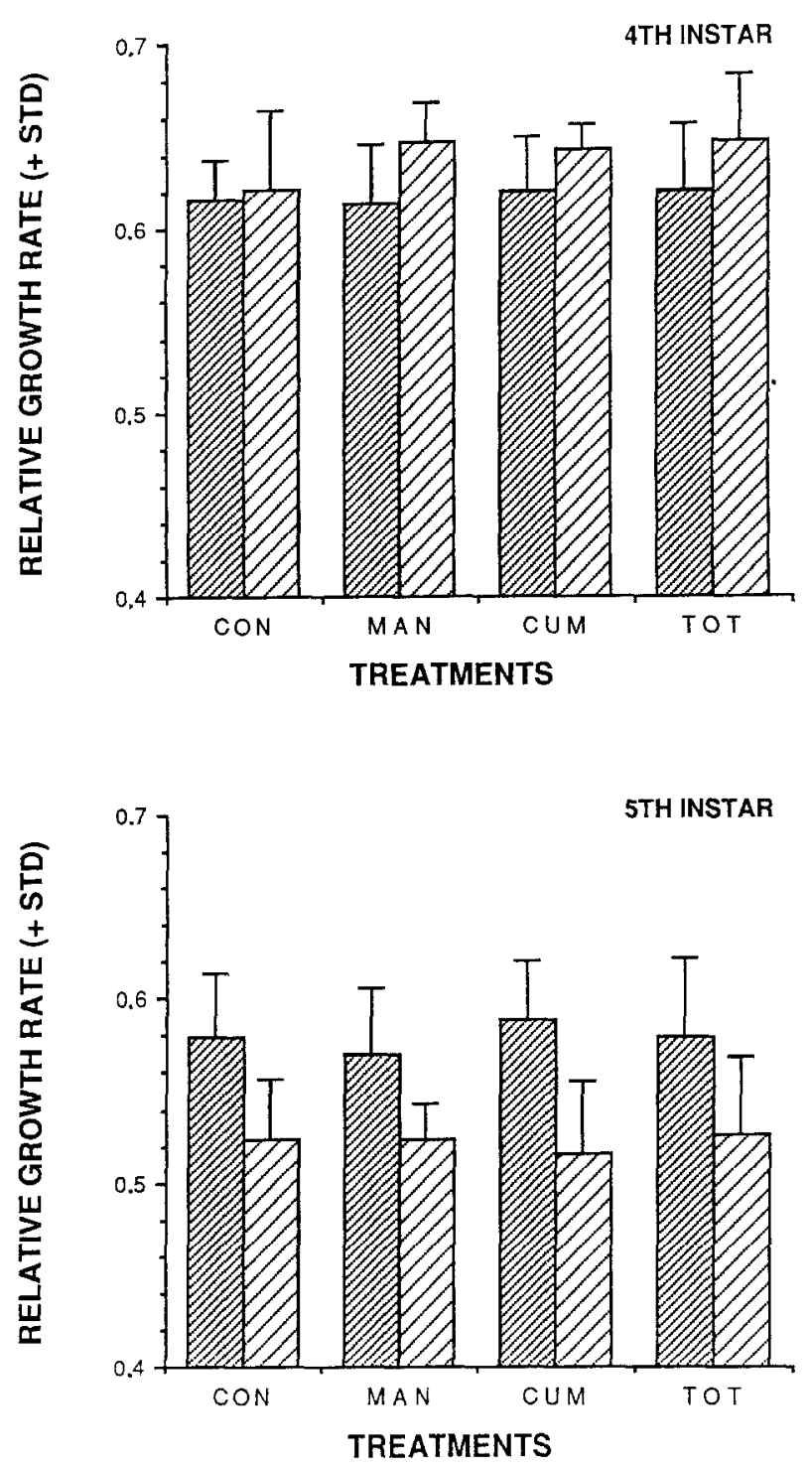

Fig. 2. Mean relative growth rates of E. autumnata larvae on leaf clusters from the same trees but tested 4 (densely hatched columns) and 13 days (sparsely hatched) after leaf damage. Growth trials were conducted on young leaves (dense hatching) and on mature leaves (sparse hatching). Treatments as in Table 1
Table 4. ANOVA results on the effect of leaf phenology and leaf damage (=treatment) on the relative growth rates of 4th and 5th instar E. autumnata larvae

\begin{tabular}{lrrrl}
\hline Source of variation & $d f$ & \multicolumn{1}{c}{ SS-III } & \multicolumn{1}{c}{$F$-ratio } & \multicolumn{1}{l}{$P$} \\
\hline Phenology & 1 & 7490.0 & 12.62 & 0.0005 \\
Treatment & 3 & 4125.1 & 2.32 & 0.0792 \\
Instar & 1 & 483733.9 & 814.74 & 0.0001 \\
Phenology $\times$ Treatment & 3 & 5091.9 & 2.86 & 0.0399 \\
Phenology $\times$ Instar & 1 & 125268.2 & 210.99 & 0.0001 \\
Treatment $\times$ Instar & 3 & 1313.1 & 0.74 & 0.5318 \\
Phenology $\times$ Treatment $\times$ Instar & 3 & 932.9 & 0.52 & 0.6668 \\
Error & 120 & 71247.5 & & \\
$\quad$ Total & 279 & 945296.6 & & \\
\hline
\end{tabular}

${ }^{a} \times 10^{-6}$. Type III sum of squares (GLM, SAS 1985)

Treatments CON, MAN, LAR and TOT were used in the analysis. The model explained $92.5 \%$ of the variance 
Table 5. Results from repeated-measures ANOVA on the effect of time since damage (4 and 13 days) and type of damage (treatments: CON, MAN, CUM and TOT) on the relative growth rates of two instars of $E$. autumnata larvae

\begin{tabular}{|c|c|c|c|c|}
\hline Source of variation & $d f$ & SS-III ${ }^{\mathrm{a}}$ & $F$-ratio & $\hat{P}$ \\
\hline \multicolumn{5}{|l|}{ Between subjects } \\
\hline Treatment & 3 & 247.2 & 1.39 & 0.2592 \\
\hline Instar & 1 & 32219.5 & 544.41 & 0.0001 \\
\hline Treatment $\times$ Instar & 3 & 273.2 & 1.54 & 0.2193 \\
\hline Error (Between subjects) & 40 & 2367.9 & & \\
\hline \multicolumn{5}{|l|}{ Within subjects } \\
\hline Time & 1 & 1632.9 & 27.09 & 0.0001 \\
\hline Time $\times$ Treatment & 3 & 429.3 & 2.37 & 0.0845 \\
\hline Time $\times$ Instar & 1 & 8358.9 & 138.66 & 0.0001 \\
\hline Time $\times$ Treatment $\times$ Instar & 3 & 220.1 & 1.22 & 0.3161 \\
\hline Error (Within subjects) & 40 & 2411.4 & & \\
\hline
\end{tabular}

${ }^{a} \times 10^{-5}$. Type III sum of squares (GLM, SAS 1985)

The same trees were tested twice, in young and mature leaf phase. RGR values given in Fig. 2
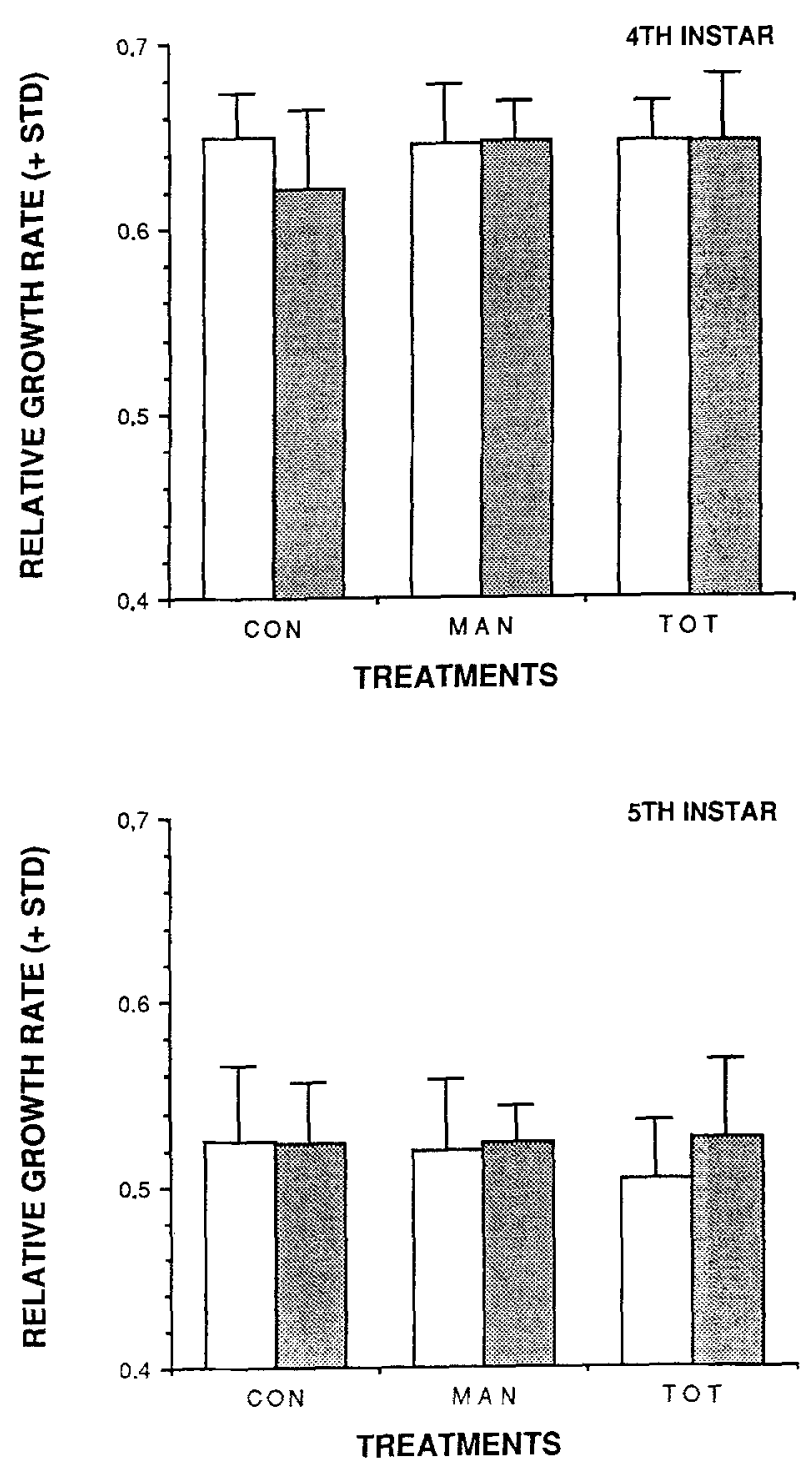

Fig. 3. Mean relative growth rates of E. autumnata larvae on leaf clusters from trees damaged either 4 (open columns) or 13 days (dark columns) before growth trials. The effect of leaf quality was tested with mature leaves. Treatments as in Table 1
Larval instars. The fourth instar larvae had higher relative growth rates than the fifth instar larvae throughout the experiments (Figs. 1-4). The interaction between instar and leaf treatment was significant in none of the cases (Tables 3-7), indicating that the larvae of the two instars responded similarly to leaf damage.

Leaf phenology interacted significantly with instar $(F=210.99, P \ll 0.0001, d f=1,120)$ (Table 4). The 4th instar larvae grew better on the new experimental trees of $\mathrm{I} 2$ in the 5 July growth trial, whereas the 5 th instar larvae had slightly reduced growth rates on these trees (Fig. 1). However, there was no significant three-level interaction between the trees in the first and second growth trial, damage type and instar that could have suggested differences in the sensitivity of larvae.

Males and females. The performance of males and females on damaged leaves was tested with some of the experimental larvae only. However, neither in the population test (Table 8) nor in the temperature-manipulation test (Table 9) did sexes differ in their relative growth rates, nor interact significantly with leaf treatment. Although there were no differences in relative growth rates between the sexes, male pupal mass was significantly smaller than that of females (temperature-manipulation test: $F=12.13$, $P=0.0007, d f=1,129$, Table 9; population test: $F=4.25$, $P=0.0539, d f=1,18$ ).

The effect of temperature manipulation. The significant phenology-by-instar interaction (Table 4) indicated differences between the two instars in responding to leaf maturation. This was caused by delaying the development of larvae with temperature manipulation. This treatment of larvae inevitably included also asynchrony with birches.

We studied the effect of temperature manipulation on larval growth by conducting a further growth trial with the delayed larvae also in their 5th instar and compared the normal and delayed larvae with each other. This comparison was based on a random lot of 133 larvae of 10 broods (out of 30) of the Kevo population. By the time of this last growth trial, which was conducted on birches from the site of the experimental trees, the delay was 
Table 6. ANOVA resuits on the effect of time since damage ( 4 and 13 days) and type of damage (treatments: CON, MAN and TOT) on the relative growth rates of two instars of E. autumnata larvae

\begin{tabular}{lrrrr}
\hline Source of variation & $d f$ & \multicolumn{1}{c}{ SS-III } & F-ratio & \multicolumn{1}{c}{$P$} \\
\hline Time & 1 & 0.2 & 0.00 & 0.9589 \\
Treatment & 2 & 87.2 & 0.67 & 0.5170 \\
Instar & 1 & 67898.5 & 1036.02 & 0.0001 \\
Time $\times$ Treatment & 2 & 529.6 & 4.04 & 0.0213 \\
Time $\times$ Instar & 1 & 352.3 & 5.38 & 0.0230 \\
Treatment $\times$ Instar & 2 & 348.4 & 2.66 & 0.0762 \\
Time $\times$ Treatment $\times$ Instar & 2 & 143.9 & 1.10 & 0.3384 \\
Error & 80 & 5243.0 & & \\
$\quad$ Total & 199 & 94900.6 & & \\
\hline
\end{tabular}

${ }^{a} \times 10^{-5}$. Type III sum of squares (GLM, SAS 1985)

Damage was done to young and mature leaves of different trees, and growth trials were conducted on mature leaves. The model explained $94.5 \%$ of the variance. RGR values given in Fig. 3
Table 7. ANOVA results on the effect of damage to young birch leaves (treatments: CON, MAN, LAR and TOT) on the relative growth rates of larvae of two E. autumnata populations

\begin{tabular}{lrrrr}
\hline Source of variation & $d f$ & \multicolumn{1}{c}{ SS-III } & F-ratio & \multicolumn{1}{c}{$P$} \\
\hline Treatment & 3 & 5257.8 & 3.55 & 0.0176 \\
Instar & 1 & 232374.1 & 470.96 & 0.0001 \\
Population & 1 & 4135.9 & 8.38 & 0.0048 \\
Treatment $\times$ Instar & 3 & 132.5 & 0.09 & 0.9656 \\
Treatment $\times$ Population & 3 & 462.0 & 0.31 & 0.8166 \\
Error & 88 & 43419.8 & & \\
$\quad$ Total & 207 & 584092.3 & & \\
\hline
\end{tabular}

${ }^{2} \times 10^{-6}$. Type III sum of squares (SAS 1985)

Two instars from the Kevo and only one from the Luftjokdalen population were tested. The model explained $92.6 \%$ of the variance. RGR values given in Fig. 4

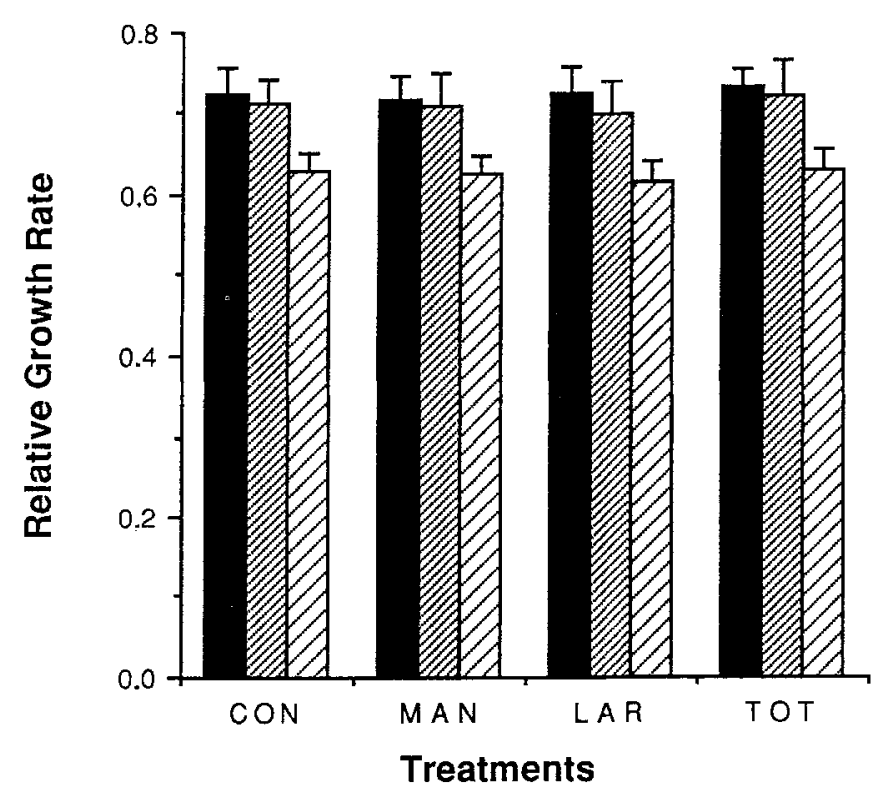

Fig. 4. Mean relative growth rates of $E$. autumnata larvae in the 26 June growth trial. Dark columns: high-density Luftjokdalen population, 4th instar; densely hatched: low-density Kevo population, 4th instar, and sparsely hatched: low-density Kevo population, 5th instar. Treatments as in Table 1

5 days compared to normally reared 5 th instar larvae. The results are given in Table 9. The 5th instar larvae grew about $21 \%$ slower when delayed 5 days. In contrast, the 4 th instar larvae of the 5 July trial grew about $6 \%$ better when delayed 9 days (compared with the 4th instar larvae of the 26 June experiment). The significant interaction between instar and temperature manipulation clearly demonstrates this (Table 9b). Furthermore, the negative effects of delaying development in the 5 th instar persisted until the pupal stage (Table 9a).

Conditioning by prior diet. To overcome the possible effects of conditioning due to prior experience with food, we reallocated the normal larvae used in the 26 June growth experiment (152 larvae out of 390) randomly to the experimental trees in the 5 July trial. These larvae were from each of the 30 Kevo broods. The food type of the first $(26$ June) growth trial should have had only a minor effect on the growth of the larvae in the second (5 July) trial, since they were removed from the experimental leaves and given fresh new leaves from a common birch between the two trials. We tested a posteriori, with a two-way ANOVA, whether the food in the first growth trial affected the outcome of the second by analyzing the relative growth rates of the 5th instar larvae in relation to their prior experience (Table 10).

The RGR values were slightly higher for larvae that were feeding on a similar type of diet in both trials (Table $10 \mathrm{a}$ ), but the difference was only marginally significant (Table 10b). However, leaf treatment and prior experience of larvae showed significant interaction, suggesting differences in larval growth due to prior experience with leaf quality (Table 10b). Because of this significant interaction, we analyzed the data set separately for both groups of larvae. The results revealed (contrasts not shown) that 
Table 8. ANOVA results on the effect of damage to young birch leaves on the relative growth rates of the 4 th instar male and female larvae of two E. autumnata populations
Table 9a. Mean relative growth rates ( $\mathrm{mg} \cdot \mathrm{mg}^{-1} \cdot \mathrm{d}^{-1}$ ) and pupal masses (mg) of E. autumnata females and males when reared normally or delayed

\begin{tabular}{lrrrr}
\hline Source of variation & $d f$ & SS-III & $F$-ratio & \multicolumn{1}{l}{$P$} \\
\hline Population & 1 & 52072.9 & 52.46 & 0.0001 \\
Treatment & 3 & 11823.7 & 3.97 & 0.0247 \\
Sex & 1 & 1838.7 & 1.85 & 0.1903 \\
Population $\times$ Treatment & 3 & 4238.9 & 1.42 & 0.2687 \\
Population $\times$ Sex & 1 & 579.7 & 0.58 & 0.4547 \\
Treatment $\times$ Sex & 3 & 3277.0 & 1.10 & 0.3746 \\
Error & 18 & 17867.9 & & \\
$\quad$ Total & 72 & 233903.4 & & \\
\hline
\end{tabular}

a $\times 10^{-6}$. Type III sum of squares (SAS 1985)

Treatments as in Table 7 . The model explained $92.4 \%$ of the variance

\begin{tabular}{|c|c|c|c|c|c|c|c|c|}
\hline \multirow[b]{2}{*}{ Females } & \multicolumn{4}{|c|}{ Normal } & \multicolumn{4}{|c|}{ Delayed $^{\mathrm{a}}$} \\
\hline & Mean & $\mathrm{SD}$ & $n$ & $\mathrm{dd} 5$ & Mean & $\mathrm{SD}$ & $n$ & $\mathrm{dd} 5$ \\
\hline $\begin{array}{l}\text { 4th instar } \\
5 \text { th instar } \\
\text { Pupal mass }\end{array}$ & $\begin{array}{l}0.618 \\
0.412 \\
76.3\end{array}$ & $\begin{array}{l}0.043 \\
0.052 \\
16.0\end{array}$ & $\begin{array}{l}31 \\
31 \\
31\end{array}$ & $\begin{array}{l}110 \\
140\end{array}$ & $\begin{array}{l}0.656 \\
0.326 \\
70.2\end{array}$ & $\begin{array}{l}0.040 \\
0.045 \\
6.4\end{array}$ & $\begin{array}{l}40 \\
40 \\
40\end{array}$ & $\begin{array}{l}140 \\
166\end{array}$ \\
\hline Males & & & & & & & & \\
\hline $\begin{array}{l}\text { 4th instar } \\
\text { 5th instar } \\
\text { Pupal mass }\end{array}$ & $\begin{array}{l}0.626 \\
0.395 \\
71.6\end{array}$ & $\begin{array}{l}0.033 \\
0.045 \\
5.7\end{array}$ & $\begin{array}{l}20 \\
20 \\
20\end{array}$ & & $\begin{array}{r}0.670 \\
0.311 \\
62.8\end{array}$ & $\begin{array}{l}0.046 \\
0.054 \\
6.8\end{array}$ & $\begin{array}{l}42 \\
42 \\
42\end{array}$ & \\
\hline
\end{tabular}

${ }^{2}$ Delay was nine for the 4th and five days for the 5 th instar larvae

b ANOVA-results: Normal vs. delayed growth $F=18.52, P=0.0001, d f=1,129 ; \operatorname{Sex} F=12.13$, $P=0.0007$; Interaction $F=0.57, P=0.4512$

Thermal sum (dd5) for the start of growth trial is given. The same individuals (from 10 broods) were measured both in the 4th and 5 th instar

\begin{tabular}{lrrrr}
\hline Source of variation & $d f$ & \multicolumn{1}{c}{ SS-III $^{\mathrm{a}}$} & $F$-ratio & \multicolumn{1}{l}{$P$} \\
\hline Manipulation & 1 & 29294.6 & 30.20 & 0.0001 \\
Sex & 1 & 389.4 & 0.40 & 0.5275 \\
$\quad$ Error (Between subjects) & 129 & 125135.1 & & \\
Instar & 1 & 4841885.0 & 1498.53 & 0.0000 \\
Instar $\times$ Sex & 1 & 11207.4 & 3.47 & 0.0648 \\
Instar $\times$ Manipulation & 1 & 241342.7 & 74.69 & 0.0001 \\
$\quad$ Error (Within subjects) & 129 & 416810.4 & & \\
Other interactions not significant & & & &
\end{tabular}

Other interactions not significant

a $\times 10^{-6}$. Type III sum of squares (SAS 1985)
Table 9b. Results from repeated-measures ANOVA on the effect of temperature manipulation (= normal vs. delayed growth) on the relative growth rates of E. autumnata larvae of different sex and instar experienced larvae (feeding on the same diet in both trials) grew slowest on LAR trees and best on canopy-widedamaged trees. The non-experienced larvae (feeding on different diets in both trials) were indifferent to leaf treatments.

\section{Discussion}

Our results show that there is a clear difference in response of birches to artificial and larval-made damage, and to damage to young versus mature leaves. The amount of damage, or its spatial distribution, seemed to be important: damage restricted to single branches retarded the growth of larvae, while canopy-wide damage did not (Table 3) or even had a weak positive effect (Figs. 1 and 2). These results suggest that the responses to damage need not be systemic, i.e. more damage meaning higher resistance, as was found in the red oak by Rossiter et al. (1988). In fact, they may not be defensive at all (see Haukioja et al. 1990). Several studies report weak, negative, no, or even positive effects on herbivores (for review see Karban and Myers 1989; Haukioja 1991). Similarly, repeated, cumulative damage to trees did not induce higher resistance than either branch-restricted or canopywide damage done once. 
Table 10a. Mean relative growth rates $\left(\mathrm{mg} \cdot \mathrm{mg}^{-1} \cdot \mathrm{d}^{-1}\right)$, standard deviation (SD) and number ( $n$ ) of 5 th instar E. autumnata larvae in the 5 July trial in relation to food in the 26 June trial

\begin{tabular}{|c|c|c|c|c|c|c|}
\hline \multirow[b]{2}{*}{$\begin{array}{l}\text { Food in } \\
\text { July } 5\end{array}$} & \multicolumn{3}{|l|}{ Same } & \multicolumn{3}{|c|}{ Different } \\
\hline & Mean & SD & $n$ & Mean & SD & $n$ \\
\hline \multicolumn{7}{|l|}{ No damage: } \\
\hline CON & 0.492 & 0.028 & 17 & 0.496 & 0.027 & 34 \\
\hline \multicolumn{7}{|l|}{$\begin{array}{l}\text { Localized } \\
\text { damage: }\end{array}$} \\
\hline $\begin{array}{l}\text { MAN } \\
\text { LAR }\end{array}$ & $\begin{array}{l}0.509 \\
0.476\end{array}$ & $\begin{array}{l}0.020 \\
0.014\end{array}$ & $\begin{array}{r}13 \\
4\end{array}$ & $\begin{array}{l}0.493 \\
0.495\end{array}$ & $\begin{array}{l}0.021 \\
0.031\end{array}$ & $\begin{array}{l}27 \\
18\end{array}$ \\
\hline \multicolumn{7}{|l|}{$\begin{array}{l}\text { Canopy-wide } \\
\text { damage: }\end{array}$} \\
\hline $\begin{array}{l}\text { CUM } \\
\text { TOT }\end{array}$ & $\begin{array}{l}0.553 \\
0.500\end{array}$ & - & $\begin{array}{l}1 \\
2\end{array}$ & $\begin{array}{l}0.489 \\
0.483\end{array}$ & $\begin{array}{l}0.027 \\
0.028\end{array}$ & $\begin{array}{l}11 \\
25\end{array}$ \\
\hline Grand mean & 0.499 & 0.026 & 37 & 0.492 & 0.027 & 115 \\
\hline
\end{tabular}

Same $=$ similar diet, Different $=$ dissimilar diet in both trials. Means are adjusted for initial larval mass

Table 10b. ANOVA results on the effect of conditioning via experience with food (same vs. different food in two subsequent growth trials) on the relative growth rates of 5 th instar E. autumnata larvae

\begin{tabular}{lrrrl}
\hline Source of variation & \multicolumn{1}{c}{$d f$} & \multicolumn{1}{c}{ SS-III $^{\mathrm{a}}$} & \multicolumn{1}{l}{$F$-ratio } & $P$ \\
\hline Conditioning & 1 & 2534.5 & 3.75 & 0.0549 \\
Treatment & 4 & 4963.0 & 1.83 & 0.1255 \\
Interaction & 4 & 7253.8 & 2.68 & 0.0341 \\
Error $\quad 142$ & 96058.3 & & \\
$\quad$ Total & 151 & 107411.5 & & \\
\hline
\end{tabular}

${ }^{a} \times 10^{-6}$. Type III sum of squares (SAS 1985)

The model explained $10.6 \%$ of the variance

\section{Plant characters}

In birch both growing young and mature leaves are present at the same time on long and short shoots, respectively. Long shoot leaves are produced continuously, whereas short shoots have a brief leaf flush period. This growth pattern of birches may bring extra variation into studies on inducible responses. Therefore, we used short shoot leaves and varied only the timing of damage.

During development, each leaf is initially a metabolic sink before gradually becoming a metabolic source (Coleman 1986). Coleman and Jones (1991) have claimed that leaves in the pre-transition or at the transition phase are most susceptible to various kinds of stresses, such as fungal attack or air pollution agents like ozone. Similarly, several herbivore species prefer leaves of this phase (Coleman 1986, for review). It is worth noting that the larval period of E. autumnata covers this transition phase of mountain birch leaves since the usual pupation date is around $260-280 \mathrm{dd} 5$, while leaf biomass accumulation is terminated at 300-327 dd5 (Ayres and MacLean 1987).
Also, the abrupt decline in growth rates of larvae coincides with the completion of leaf maturation $(170-228 \mathrm{dd} 5$ in Ayres and MacLean 1987; 166 dd5 in the present study, Table 9). However, not many studies have attempted to report the effects of damage to leaves of sink-source transition which may reflect the difficulties in carrying out well-controlled experiments (but see Coleman 1986).

Other studies have shown, too, that young growing leaves respond to damage but mature leaves do not (Edwards and Wratten 1987; Hartley and Lawton 1991). The results of Haukioja and Niemelä (1979) suggested the same, although their experimental design did not allow discrimination between the effects of timing of damage and possible differences in experimental insect species. Neuvonen et al. (1988) found no retardation in growth of Dineura virididorsata (Retzius) larvae, a late season sawfly species, when leaves were damaged in mid-July (at $350 \mathrm{dd} 5$ ). Several other sawfly species of the mountain birch were reported to show retarded growth because of inducible responses in young leaves (Hanhimäki 1989).

Since leaf ontogeny seems to affect the strength of reactions to damage (Coleman 1986) and since these reactions may modify the performance of other herbivorous insects sharing the same host plant (West 1985; Faeth 1986; Silkstone 1987; Neuvonen et al. 1988; Brody and Karban 1989; Hanhimäki 1989; Karban and EnglishLoeb 1990), experiments on RIR at the beginning of the growth season are critical for understanding the ecological consequences of inducible responses.

In the present study, damage to single branches induced stronger responses of resistance than canopy-wide damage. Large-scale damage had no effect or caused a slight amelioration of leaf quality (RGRs of larvae were highest on canopy-wide damaged trees) (Fig. 1a). This was an unexpected result.

In general, small amounts of damage have been considered to be unimportant for trees (but see Crawley 1985) and for herbivores (Fowler and Lawton 1985). Fowler and Lawton (1985, Fig. 1) gave evocative evidence on this scale-of-damage effect in their field test. Birches that had experienced $25 \%$ artificially caused leaf-loss (every other leaf torn in half) were subjected to more subsequent damage by natural herbivory than saplings whose every tenth leaf was damaged $(5 \%$ leaf-loss estimated for whole saplings). Hence, large-scale damage could have caused amelioration of leaf quality while small-scale damage caused a slight decline.

Large-scale damage may mean a high herbivore density, and need for effective inducible resistance. At this stage, however, rapid inducible resistance may be ineffective, and trees can show resistance only in the following year(s), i.e. delayed resistance. In addition, elevation of resistance may be physiologically constrained (see also Marquis 1991), especially, if the season is cold: the thermai sum at Kevo in 1987 was one of the five coldest according to the 28-year statistics of the Kevo Meteorological Station (Monthly Report from the Finnish Meteorological Institute). Interestingly, Fowler and Lawton (1985) mentioned that the (early) season was exceptionally cold and wet during their treatment application. Damage concentrated on only a few branches, or when only a small amount of leaf biomass has been removed, may be physi- 
ologically and "economically" manageable for birches in such situations. Furthermore, it is possible that there are differences among the hierarchical units of plants (shoots, branches, ramets etc.) and in their interaction with external factors in responding to leaf damage (Marshall 1989; Tuomi and Vuorisalo 1989; Haukioja et al. 1990; Sprugel et al. 1991).

Theoretically, a relaxation of induced resistance should be expected. Unfortunately, the effect of earlier larval damage (the treatment showing the strongest impact) could not be tested a second time because branches lacked leaf clusters with larval feeding marks. When trees, artificially damaged at the young leaf phase, were tested a second time, we found no significant treatment effect nor interaction with time (Table 5). However, when trees damaged at the young or mature leaf phase were analyzed, we found a significant interaction with treatment and time (Table 6). This latter result emphasizes leaf age at time of damage, since leaves were tested at a similar age. However, there were no clear trends, either retarding or enhancing effects on larval growth, and the time-by-treatment interaction could have been confounded by the differences between the two larval instars (Table 6). Hence, it is difficult to judge confidently whether the response to damage to young leaves relaxes rapidly or within 13 days.

Evidence on rapid relaxation of inducible responses has been found in other experiments, e.g. with tobacco (Baldwin 1988b) and with birches, but the relaxation time varies according to what has been measured (Wratten et al. 1984; Bergelson et al. 1986; Edwards et al. 1986; Hartley and Lawton 1987; Hartley and Firn 1989). Two mid-season sawfly species of the mountain birch insect guild showed retarded growth on excised leaves from trees that had had E. autumnata larvae growing in bags on branches (and causing RIR) (Hanhimäki 1989). Leaves were tested 4-7 days after E. autumnata larvae had ceased feeding. Other late-season herbivore species were not significantly affected by RIR when tested later than 7 days (Hanhimäki 1989), which makes relaxation of RIR probable.

\section{Triggering agent}

Recently, Baldwin (1990) reviewed plant-herbivore studies in which larval-made and artificial damage had been used, and concluded that larval damage was the most effective to cause inducible responses in plants (but see Welter 1991). Hartley and Lawton (1987) reported significant preferences of various insect herbivores for undamaged control birch leaves when damage was caused by leaf miners. Furthermore, Hartley and Firn (1989) demonstrated larger and longer-lasting increase in phenolic levels in insect-grazed Betula pendula Roth leaves compared to artificially damaged ones. Hartley and Lawton (1991) suggested that larval saliva may contain fungal spores of hyphae which, when interacting with plant cell wall fragments, may cause this phenomenon. Whatever the reasons for the differing effects of artificial and natural leaf damage are, the main point is that this difference should not be ignored in plant-herbivore studies.

\section{Test animals}

In general, the quality of test animals has been ignored in plant-herbivore studies. Very often larvae have been collected from the field (parasitized or unparasitized larvae), or mass-reared laboratory individuals have been used (Spodoptera spp.), although both these cases may give wrong information on the sensitivity of test animals (Orr and Boethel 1985; Haukioja et al. 1988b). The different sensitivity of larvae may have some obvious implications for studies in which bioassays are used to detect (small) leaf quality differences (see Wolfson 1988). For instance, if leaf quality changes are rapid and/or relax rapidly, the effects of induced responses may not be detected with late instar larvae. On the other hand, if leaf quality changes are slow (regardless of the length of relaxation time), the effects may not be detected with early instar larvae.

Instars. Larval age, although supposed to be important (Neuvonen and Haukioja 1984), has received little attention in studies on plant-herbivore interactions and especially in relation to leaf damage (but see Rossiter et al. 1986). In the present study we found that the two instars of the autumnal moth responded similarly to leaf damage (Tables 2-7) but differently to temperature manipulation (or leaf maturation, Table 9). We used larvae of the last two instars, and this does not mean that all other instars are similarly affected. In fact, in field cages, where predation and parasitism have been eliminated, most mortality of $E$. autumnata larvae takes place during the first two instars, suggesting pronounced effects of leaf quality on young larvae (Neuvonen and Haukioja 1984; E. Haukioja et al., unpubl. data). Consequently, our results are conservative in detecting differences between instars.

Delaying larval growth had a stronger retarding effect on the 5th than on the 4th instar larvae (Table 9). The two instars might have been differently sensitive to changes in leaf quality. Therefore, it was important to test them simultaneously throughout the experiment. The 4th instar larvae were 9 days delayed when tested on mature leaves, but still they had a $5.1 \%$ higher growth rate than the normally growing 4th instar larvae on young leaves (Fig. 1). This shows that keeping the larvae at low temperature had not hindered their ability to grow rapidly when conditions improved. The growth of these delayed larvae, however, was significantly retarded in the 5 th instar, and at the end they attained lower pupal masses than the normally growing larvae (Table 9a).

Broods. In plant-herbivore studies, in which seasonal effects have been investigated with the same herbivore species, different broods have often been used at different times (e.g. Strauss 1990). In such cases it is impossible to know whether the observed differences are caused by seasonal changes in plants (leaf maturation, flowering etc.) or by test animals. Since we always had the same broods (of the low-density Kevo population) in both young and mature leaf experiments, we could avoid this source of error. Nevertheless, brood-specific differences in growth rates of $E$. autumnata larvae are generally modest or non-existent (Ayres et al. 1987), though within a brood can be clear differences among larvae according to their 
hatching schedule (S. Hanhimäki and E. Haukioja, unpubl. data).

Populations. The population from which E. autumnata larvae were derived had a significant effect on the growth of larvae (Tables 7 and 8). Larvae from the high-density population had higher relative growth rates than larvae from the low-density population. Interestingly, population of the test larvae did not interact with the effects of leaf damage (Tables 7 and 8). This suggests that leaf responses influence all autumnal moth larvae independently of the population. The same result has repeatedly been found in other experiments with $E$. autumnata (Haukioja and Hanhimäki 1985; Haukioja et al. 1990; Ruohomäki and Haukioja 1992). Similarly, males and females of the autumnal moth differed in their pupal mass, but the relative growth rates of sexes did not, nor interact with leaf damage (Tables 8 and 9).

Conditioning of larvae. Conditioning of herbivore larvae via different food qualities has received little attention from entomologists (but see Jermy et al. 1968; Hansen 1976). We found a significant interaction between prior experience with food type and the subsequent growth of larvae (Table 10b). In the 5 July trial, in which damage to mature leaves was tested and no difference found (Table $3 \mathrm{~b}$ ), the same response of leaves could be observed, but only when prior experience of the test larvae was taken into account. Larvae which were fed with similar larvaldamaged leaves in both trials had the slowest growth, whereas those fed twice with canopy-wide-damaged leaves had significantly better growth than either with control or small-scale-damaged leaves. However, replication was low and only $10.6 \%$ of the variance could be explained by the model (Table 10b). Judging the importance of this result on the whole experiment $(9.5 \%$ of the larvae of the 5 July trial were on similar diets in both trials), we feel that conditioning of larvae had only a minor, if any, effect on the outcome of the second induction experiment.

\section{Conclusions}

Our results indicate that the ontogenetic phase of the leaves may shape the response to damage and that the triggering agent is important. The pattern of responses suggests that there may be physiological constraints: small-scale damage induced resistance against the autumnal moth, but large-scale damage did not. It is possible that high herbivore density (indicated by canopy-wide damage) may cause the trees' resistance system to succumb, as in bark beetle attacks on conifers (Raffa and Berryman 1983). As a consequence, plant quality for herbivores may even improve.

Responses of birches to leaf damage were not straightforward: both resistance and improvement of leaf quality could be elicited. We should, thus, speak of rapidly inducible responses (Karban and Myers 1989) rather than of resistance (or even defense), this latter already implying our predictions about the outcome and nature of events (Owen 1990).
Population, instar or sex of the test animals did not interact with leaf damage. However, there were indications that prior experience of larvae with experimental leaves may modify their responses in further bioassays. This aspect deserves more attention in future plant-herbivore studies. Our results showed that variation found in studies on rapidly inducible responses in the mountain birch depends on plant characteristics rather than on experimental animals.

Acknowledgements. This study could not have been possible without A. Sydänoja nor the excellent working facilities of the Kevo Station. M. Halme and C. Tobin tore leaves with us. Discussions with E. Haukioja, J. Lawton, S. Neuvonen, H. Müller, K. Ruohomäki, and J. Suomela helped us to clarify our thoughts on this subject. S. Neuvonen and K. Ruohomäki shared generously their expertise on statistical problems. The comments of E. Haukioja, M. Komulainen, H. Müller, S. Neuvonen, A. van Noordweijk, S. Stearns, J. Suomela, G. Walter and two anonymous referees improved the earlier drafts of the manuscript. G. Walter also polished the language. The study was supported by the Emil Aaltonen Foundation to SH and by the Finnish Ministry of Education to JS. The manuscript was partly written while SH was at the Zoological Institute of the University of Basle with the financial support of the Schweizerische Stipendienkommission.

\section{References}

Ayres MP, MacLean SF Jr (1987) Development of birch leaves and the growth energetics of Epirrita autumnata (Geometridae). Ecology 68: $558-568$

Ayres MP, Suomela J, MacLean SF Jr (1987) Growth performance of Epirrita autumnata (Lepidoptera: Geometridae) on mountain birch: trees, broods, and tree $\times$ brood interactions. Oecologia 74: $450-457$

Baldwin IT (1988a) Damage-induced alkaloids in tobacco: potbound plants are not inducible. J Chem Ecol 4: 1113-1120

Baldwin IT (1988b) Short-term damage-induced increases in tobacco alkaloids protect plants. Oecologia 75: $367-370$

Baldwin IT (1990) Herbivory simulations in ecological research. Trends Ecol Evol 5: 91-93

Bergelson J, Fowler S, Hartley S (1986) The effects of foliage damage on casebearing moth larvae, Coleophora serratella, feeding on birch. Ecol Entomol 11: 241-250

Broadway RM, Duffey SS, Pearce G, Ryan CA (1986) Plant proteinase inhibitors: A defense against herbivorous insects? Entomol Exp Appl 41: 33-38

Brody AK, Karban R (1989) Demographic analysis of induced resistance against spider mites (Acari: Tetranychidae) in cotton. J Econ Entomol 82: 462-465

Coleman JS (1986) Leaf development and leaf stress: increased susceptibility associated with sink-source transition. Tree Physiol 2: 289-299

Coleman JS, Jones CG (1991) A phytocentric perspective of phytochemical induction by herbivores. In: Tallamy DW, Raupp MJ (eds) Phytochemical Induction by Herbiyores. John Wiley \& Sons, pp 3-45

Crawley MJ (1985) Reduction of oak fecundity by low density herbivore population. Nature 314: $163-164$

Edwards PJ, Wratten SD (1983) Wound-induced defences in plants and their consequence for patterns of insect grazing. Oecologia 59: $88-93$

Edwards PJ, Wratten SD (1985) Induced plant defences against insect grazing: fact or artefact? Oikos 44: 70-74

Edwards PJ, Wratten SD (1987) Ecological significance of woundinduced changes in plant chemistry. In: Labeyrie V, Fabres G, Lachaise D (eds) Proceedings of the Sixth International Symposium on Insect-Plant Relationships. W. Junk Publisher, pp $213-218$ 
Edwards PJ, Wratten SD, Cox H (1985) Wound-induced changes in the acceptability of tomato to larvae of Spodoptera littoralis: a laboratory bioassay. Ecol Entomol 10: 155-158

Edwards PJ, Wratten SD, Greenwood S (1986) Palatability of British trees to insects: constitutive and induced defences. Oecologia 69: $316-319$

Faeth SH (1986) Indirect interactions between temporally-separated herbivores mediated by the host plant. Ecology 67: 479-494

Fowler SV (1984) Foliage value, apparency and defence investment in birch seedlings and trees. Oecologia 62: 387-392

Fowler SV, Lawton JH (1985) Rapidly induced defenses and talking trees: the Devil's advocate position. Am Nat 126: 181-195

Fowler SV, McGarvin M (1986) The effects of leaf damage on the performance of insect herbivores on birch, Betula pubescens. J Anim Ecol 55: 565-573

Gibberd R, Edwards PJ, Wratten SD (1988) Wound-induced changes in the acceptability of tree-foliage to Lepidoptera: within-leaf effects. Oikos 51: 43-47

Green TR, Ryan CA (1972) Wound-induced proteinase inhibitor in plant leaves: a possible defense against insects. Science 175: $776-777$

Hanhimäki S (1989) Induced resistance in mountain birch: defence against leaf-chewing insect guild and herbivore competition. Oecologia 81: 242-248

Hansen FE (1976) Comparative studies on induction of food choice preferences in lepidopteran larvae. In: Jermy $\mathrm{T}$ (ed) The hostplant relation to insect behaviour and reproduction. Akademiai Kiado, Budapest, pp 71-77

Hartley SE (1988) The inhibition of phenolic biosynthesis in damaged and undamaged birch foliage and its effect on insect herbivores. Oecologia 76: 65-70

Hartley SE, Firn RD (1989) Phenolic biosynthesis, leaf damage, and insect herbivory in birch (Betula pendula). J Chem Ecol 15: $275-283$

Hartley SE, Lawton JH (1987) Effects of different types of damage on the chemistry of birch foliage, and the responses of birch feeding insects. Oecologia 74: 432-437

Hartley SE, Lawton JH (1991) Biochemical aspects and significance of the rapidly induced accumulation of phenolics in birch foliage. In: Tallamy DW, Raupp MJ (eds) Phytochemical induction by herbivores. John Wiley \& Sons, New York, pp 105-132

Haukioja E (1980) On the role of plant defences in the fluctuation of herbivore populations. Oikos 35: 202-289

Haukioja E (1982) Inducible defences of white birch to a geometrid defoliator, Epirrita autumnata. In: Visser JH, Minks AK (eds) Proceedings of the 5th international Symposium on Insect-Plant Relationships. Pudoc, Wageningen, pp 199-203

Haukioja E (1991) Induction of defenses in trees. Annu Rev Entomol 36: $25-42$

Haukioja E, Hanhimäki S (1985) Rapid wound-induced resistance in white birch (Betula pubescens) foliage to the geometrid Epirrita autumnata: a comparison of trees and moths within and outside the outbreak range of the moth. Oecologia 65: 223-228

Haukioja E, Neuvonen S (1985) Induced long-term resistance of birch foliage against defoliators: defensive or incidental? Ecology 66: $1303-1308$

Haukioja E, Niemelä P (1977) Retarded growth of a geometrid larva after mechanical damage to leaves of its host tree. Ann Zool Fenn 14: $48-52$

Haukioja E, Niemelä P (1979) Birch leaves as a resource for herbivores: Seasonal occurrence of increased resistance in foliage after mechanical damage of adjacent leaves. Oecologia 39 $151-159$

Haukioja E, Niemelä P, Kapiainen K (1983) Herbivory and tree line birches. In: Morriset P, Payette S (eds) Tree-Line Ecology. Proceedings of the Northern Quebec Tree-Line Conference. Centre d'études nordiques, Université Laval, Quebec, pp 153-158

Haukioja E, Suomela J, Neuvonen S (1985) Long-term inducible resistance in birch foliage: triggering cues and efficacy on a defoliator. Oecologia 65: 363-369

Haukioja E, Neuvonen S, Hanhimäki S, Niemelä P (1988a) The autumnal moth in Fennoscandia. In: Berryman AA (ed) Dynamics of Forest Insect Populations: Patterns, Causes, and Implications. Plenum Press, New York, pp 163-178

Haukioja E, Pakarinen E, Niemelä P, Iso-Iivari L (1988b) Crowding-triggered phenotypic responses alleviate consequences of crowding in Epirrita autumnata (Lep, Geometridae) Oecologia 75: $549-558$

Haukioja E, Ruohomäki K, Senn J, Suomela J, Walls M (1990) Consequences of herbivory in the mountain birch (Betula pubescens ssp tortuosa): importance of the functional organization of the tree. Oecologia 82: 238-247

Hurlbert SH (1984) Pseudoreplication and the design of ecological field experiments. Ecol Monogr 54: 187-211

Jermy T, Hanson FE, Dethier VG (1968) Induction of specific food preference in lepidopterous larvae. Entomol Exp Appl 11: $211-230$

Karban R (1987) Herbivory dependent on plant age: a hypothesis based on acquired resistance. Oikos 48: $336-337$

Karban R, Carey JR (1984) Induced resistance of cotton seedlings to mites. Science $225: 53-54$

Karban R, English-Loeb GM (1990) A "vaccination" of Willamette spider mites (Acari: Tetranychidae) to prevent large populations of Pacific spider mites on grapevines. J Econ Entomol 83: 2252-2257

Karban R, Myers JH (1989) Induced plant responses to herbivory. Annu Rev Ecol Syst 20: 331-348

Karban R, Brody AK, Schnathorst W (1989) Crowding and a plant's ability to defend itself against herbivores and diseases. Am Nat 134: $749-760$

Kennedy CEJ, Southwood TRE (1984) The number of species of insects associated with British trees: a re-analysis. J Anim Ecol 53: $455-478$

Lawton JH (1986) Food-shortage in the midst of apparent plenty?: The case for birch-feeding insects. In: Velthuis HHW (ed) Proceedings of the 3rd European Congress of Entomology, Amsterdam, pp 219-228

Marquis RJ (1991) Physiological constraints on response by Ostrya virginiana (Betulaceae) to localized folivory. Can $\mathbf{J}$ Bot 69: $1951-1955$

Marshall DL (1989) Integration of response to defoliation within plants of two species of Sesbania. Funct Ecol 3: 207-214

Neuvonen S, Haukioja E (1984) Low nutritive quality as defence against herbivores: induced responses in birch. Oecologia 63: $71-74$

Neuvonen S, Haukioja E (1985) How to study induced plant resistance? Oecologia 66: 456-457

Neuvonen S, Haukioja E (1991) The effects of inducible resistance in host foliage on birch-feeding herbivores. In: Tallamy DW, Raupp MJ (eds) Phytochemical Induction by Herbivores. John Wiley \& Sons, pp 277-291

Neuvonen S, Haukioja E, Molarius A (1987) Delayed indueible resistance in four deciduous tree species. Oecologia 74: 363-369

Neuvonen S, Hanhimäki S, Suomela J, Haukioja E (1988) Early season damage to birch foliage affects the performance of a late season herbivore. J Appl Entomol 105: 182-189

Niemelä P, Aro E-M, Haukioja E (1979) Birch leaves as a resource for herbivores. Damage-induced increase in leaf phenols with trypsin-inhibiting effects. Rep Kevo Subarct Res Stat 15: 37-40

Orr DB, Boethel DJ (1985) Comparative development of Copidosoma truncatellum (Hymenoptera: Encyrtidae) and its host, Pseudoplusia includens (Lepidoptera: Noctuidae), on resistant and susceptible soybean genotypes. Environ Entomol 14: 612-616

Owen DF (1990) The language of attack and defence. Oikos 57: $133-135$

Raffa KF, Berryman AA (1983) The role of host plant resistance in the colonization behaviour and ecology of bark beetles (Coleoptera: Scolytidae). Ecol Monogr 53: 27-49

Raupp MJ, Denno RF (1984) The suitability of damaged willow leaves as food for the leaf beetle, Plagiodera versicolora. Ecol Entomol 9: 443-448 
Raupp MJ, Sadof CS (1989) Behavioral responses of a leaf beetle to injury-related changes in its salicaceous host. Oecologia 80 $154-157$

Rossiter M, Gerhenzon J, Mabry TJ (1986) Behavioral and growth responses of specialist herbivore Homoeosoma electellum to major terpenoid of its host, Helianthus spp. J Chem Ecol 12: $647-658$

Rossiter MC, Schultz JC, Baldwin IT (1988) Relationships among defoliation, red oak phenolics, and gypsy moth growth and reproduction. Ecology 69: 267-277

Ruohomäki K, Haukioja E (1992) Interpopulation differences in pupal size and fecundity are not associated with occurrence of outbreaks in Epirrita autumnata (Lepidoptera, Geometridae) Ecol Entomol 17; 69-75

Ruohomäki K, Hanhimäki S, Haukioja E, Iso-livari L, Neuvonen S, Niemelä P, Suomela J (1992) Variability in the efficacy of delayed inducible resistance in mountain birch. Entomol Exp Appl 62: $107-115$

SAS (1985) SAS user's guide: Statistics. SAS Institute, Cary, North Carolina

Schultz JC, Baldwin IT (1982) Oak leaf quality declines in response to defoliation by gypsy moth larvae. Science $217: 149-151$

Silkstone BE (1987) The consequences of leaf damage for subsequent insect grazing on birch (Betula spp.). A field experiment. Oecologia 74 : 149-152

Sokal RR, Rohlf FJ (1981) Biometry, 2nd edn. Freeman, San Francisco

Sprugel DG, Hinckley TM, Schaap W (1991) The theory and practice of branch autonomy. Annu Rev Ecol Syst 22: 309-334

Strauss SY (1990) The role of plant genotype, environment and gender in resistance to a specialist chrysomelid herbivore. Oecologia 84: 111-116
Tenow O (1972) The outbreaks of Oporinia autumnata Bkh. and Operophthera spp. (Lep., Geometridae) in the Scandinavian mountain chain and northern Finland 1862-1968. Zool Bidr Uppsala, Suppl 2: 1-107

Tenow O (1975) Topographical dependence of an outbreak of Oporinia autumnata Bkh. (Lep., Geometridae) in a mountain birch forest in northern Sweden. Zoon 3: 85-110

Tenow O, Nilssen A (1990) Egg cold hardiness and topoclimatic limitations to outbreaks of Epirrita autumnata in northern Fennoscandia. J Appl Ecol 27: 723-734

Thompson JN, Wehling W, Podolsky R (1990) Evolutionary genetics of host use in swallowtail butterflies. Nature 344: 148-150

Tuomi J, Vuorisalo T (1989) Hierarchical selection in modular organisms. Trends Evol Ecol 4: 209-213

Valentine HT, Wallner WE, Wargo PM (1983) Nutritional changes in host foliage during and after defoliation and their relation to the weight of gypsy moth pupae. Oecologia 57: 298-302

Welter SC (1991) Responses of tomato to simulated and real herbivory by tobacco hornworm (Lepidoptera: Sphingidae). Environ Entomol 20: 1537-1541

West C (1985) Factors underlying the late seasonal appearance of the lepidopterous leaf-mining guild on oak. Ecol Entomol 10: $111-120$

Wolfson JL (1988) Bioassay techniques. An ecological perspective. J Chem Ecol 14: 1951-1963

Wratten SD, Edwards PJ, Dunn I (1984) Wound-induced changes in the palatability of Betula pubescens and B. pendula. Oecologia 61: $372-375$

Wratten SD, Edwards PJ, Winder L (1988) Insect herbivory in relation to dynamic changes in host plant quality. Biol J Linn Soc 35: $339-350$ 